\title{
AORTIC VALVE REPLACEMENT WITH STENTLESS AND STENTED PORCINE VALVES: A CASE- MATCH STUDY
}

Tirone E. David, MD

Rudolph Puschmann, MD

Joan Ivanov, MSc

Joanne Bos, RN

Susan Armstrong, MSc

Christopher M. Feindel, MD

Hugh E. Scully, MD

\begin{abstract}
Objectives: To assess the potential benefits of the hemodynamic superiority of stentless valves, we conducted a case-match study among patients who underwent aortic valve replacement with two types of porcine bioprostheses: the Toronto SPV and the stented Hancock II bioprosthesis. Methods: Preoperative clinical variables predictive of death after aortic valve replacement were determined by a stepwise logistic regression analysis in a series of 908 consecutive patients who received porcine aortic bioprostheses during a 14-year interval. Advanced age, New York Heart Association functional class IV, left ventricular ejection fraction of less than $30 \%$, and coronary artery disease were independent predictors of death. On the basis of these four variables, 198 pairs of patients who survived aortic valve replacement with stentless and stented porcine valves were matched. The follow-up, truncated to the shortest interval for each matched pair, was $43 \pm 24$ months for both groups. Results: At 8 years the actuarial survival was $91 \% \pm 4 \%$ for the Toronto SPV group and $69 \% \pm 8 \%$ for the Hancock II group $(p=0.006)$; the freedom from cardiac-related death was $95 \% \pm 4 \%$ for the Toronto SPV and $81 \% \pm 8 \%$ for the Hancock II $(\boldsymbol{p}=\mathbf{0 . 0 1})$; the freedom from any valve-related complication was $81 \% \pm 5 \%$ for the Toronto SPV and $50 \% \pm 10 \%$ for the Hancock II $(p=$ 0.008). A Cox proportional hazard model demonstrated a significant reduction in cardiac mortality rates and valve-related morbidity in patients who received the Toronto SPV bioprosthesis. Conclusions: Although it is possible that confounding factors may have played a role in the clinical outcomes of this case-control study, the study suggests that aortic valve replacement with a stentless porcine valve enhances survival. This is believed to be due to the hemodynamic superiority of these valves. (J Thorac Cardiovasc Surg 1998;116:236-41)
\end{abstract}

$T_{1}^{\text {he }}$ he Toronto SPV bioprosthesis (St. Jude Medical, Inc., St. Paul, Minn.) was developed to improve the hemodynamic performance of porcine aortic valves and to enhance their durability. ${ }^{1,2}$ The Toronto SPV bioprosthesis is minimally obstructive to blood flow; when implanted in patients with increased left ventricular mass, it allows for complete remodeling of the left ventricle within the first 3 years. ${ }^{3}$ Color Doppler assessment of blood flow across the Toronto SPV bioprosthesis indicates that it resembles that of a

From the Divisions of Cardiovascular Surgery of The Toronto Hospital and the University of Toronto, Toronto, Ontario, Canada.

Received for publication Feb. 13, 1998; revisions requested March 26, 1998; revisions received April 13, 1998; accepted for publication April 13, 1998.

Address for reprints: Tirone E. David, MD, 200 Elizabeth St.-13EN219, Toronto, Ontario, Canada M5G 2 C4.

Copyright (C) 1998 by Mosby, Inc.

$0022-5223 / 98 \$ 5.00+0 \quad \mathbf{1 2 / 1 / 9 0 8 6 2}$ normal aortic valve. ${ }^{4}$ The hemodynamic superiority of this valve has been documented by several investigators. $^{3-5}$ Although the issue of the durability of this bioprosthesis remains unknown, our experience with 29 custom-made stentless porcine aortic valves suggests that its durability may not be better than that of stented bioprostheses. ${ }^{6}$ Thus the only obvious advantage of a stentless porcine aortic valve is its hemodynamic performance. This may be important for late survival after aortic valve replacement because persistent left ventricular hypertrophy is associated with an increased risk of death. ${ }^{7,8}$

This study was carried out to compare the late outcomes of aortic valve replacement with stentless and stented porcine aortic valves.

\section{Patients and methods}

From 1982 to 1996, 908 patients underwent isolated aortic valve replacement (AVR) with two types of porcine aortic valves at The Toronto Hospital. The Hancock II 
bioprosthesis (Medtronic, Minnesota, Minn.) was used in 666 patients, and the Toronto SPV bioprosthesis was used in 242 patients. The Hancock II bioprosthesis was used throughout the period of study whereas the Toronto SPV bioprosthesis was used only since 1987. All patients were followed up at annual intervals, and only eight patients with the Hancock II and one patient with the Toronto SPV bioprosthesis were lost to follow-up.

The Toronto SPV bioprosthesis was an investigational device during this study, and it was implanted in patients who fulfilled the following requirements: older than 34 years of age, no active aortic valve infection, no renal failure requiring dialysis, and an expected life span of at least 2 years. The Hancock II was implanted whenever appropriate. Because of these differences in patient selection, a case-control study was developed on the basis of preoperative variables predictive of death after AVR. These variables were identified by a stepwise logistic regression analysis for the entire patient population with porcine bioprostheses. The following preoperative variables were independent predictors of death after AVR: advanced age, New York Heart Association functional class IV, left ventricular ejection fraction below $30 \%$, and coronary artery disease. With this information, a casematch study was developed on the basis of the patients' age ( \pm 5 years), New York Heart Association functional class (I, II, III together, or IV ), left ventricular ejection fraction (higher or lower than $30 \%$ ), and coronary artery disease. Only survivors of the operation were entered into the case-match study. One hundred ninety-eight pairs of patients were matched. Table I shows the clinical profile of the matched patients. Both groups had the same incidence of associated diseases, such as peripheral vascular disease, diabetes, hypertension, and chronic obstructive lung disease. There were no differences in the intraoperative management of patients as far as conduction of anesthesia, cardiopulmonary bypass, or myocardial protection.

The follow-up was complete in all patients. Because the duration of the follow-up was different for the two groups of patients, follow-up times were truncated to the shortest interval for each matched pair of patients. For this reason, the mean follow-up was $43 \pm 24$ months (range 3 to 109 months) for both groups. Postoperative complications were analyzed according to the "Guidelines for Reporting Morbidity and Mortality after Cardiac Valvular Operations." 9 Events occurring after a truncated follow-up interval were censored.

All statistical analyses were performed with the SAS (SAS Institute, Inc., Cary, N.C.) and the BMDP/DYN (BMDP Statistical Software, Berkeley, Calif.) programs. The clinical profile of the two groups was compared by $\chi^{2}$ analysis. Longitudinal data, such as actuarial survival and freedom from morbid events, were estimated by the product-limit or by the Kaplan-Meier method. Values were expressed as means and the standard errors of the means. The longitudinal comparisons of the two groups of patients were evaluated by the Mantel-Cox statistic. The risk-adjusted benefit of the Toronto SPV bioprosthesis was evaluated multivariately in a Cox proportional hazard model.
Table I. Clinical profile of matched patients

\begin{tabular}{|c|c|c|c|}
\hline & $\begin{array}{c}\text { Toronto } \\
\text { SPV }\end{array}$ & $\begin{array}{c}\text { Hancock } \\
\text { II }\end{array}$ & $\begin{array}{c}p \\
\text { Value }\end{array}$ \\
\hline No. of patients & 198 & 198 & \\
\hline Age $(\mathrm{yr})^{*}$ & $62 \pm 11$ & $62 \pm 11$ & 0.66 \\
\hline Range & $34-80$ & $29-80$ & \\
\hline \multicolumn{4}{|l|}{ Sex } \\
\hline Male $(\%)$ & $135(68)$ & $145(73)$ & 0.27 \\
\hline Female $(\%)$ & $63(32)$ & $53(27)$ & \\
\hline Atrial fibrillation/flutter (\%) & $12(6)$ & $12(6)$ & 1.00 \\
\hline \multicolumn{4}{|l|}{ New York Heart Association } \\
\hline Functional class I, II, III (\%) & $172(87)$ & $172(87)$ & 0.99 \\
\hline Functional class IV (\%) & $26(13)$ & $26(13)$ & \\
\hline \multicolumn{4}{|l|}{$\begin{array}{l}\text { Left ventricular ejection } \\
\text { fraction }\end{array}$} \\
\hline$>30 \%(\%)$ & $164(83)$ & $164(83)$ & 0.99 \\
\hline$\leq 30 \%(\%)$ & $34(17)$ & $34(17)$ & \\
\hline Coronary artery disease $(\%)$ & $63(32)$ & $63(32)$ & 0.99 \\
\hline Single vessel & 12 & 11 & \\
\hline Double vessel & 14 & 14 & \\
\hline Triple vessel & 37 & 38 & \\
\hline \multicolumn{4}{|l|}{ Aortic valve lesion } \\
\hline Stenosis $(\%)$ & $148(74)$ & $94(47)$ & \\
\hline Insufficiency (\%) & $25(13)$ & $54(27)$ & 0.001 \\
\hline Mixed $(\%)$ & $25(13)$ & $49(13)$ & \\
\hline \multicolumn{4}{|l|}{ Bioprosthesis size $(\mathrm{mm})$} \\
\hline $19(\%)$ & 1 & 0 & 0.001 \\
\hline $21(\%)$ & $4(2)$ & $10(5)$ & \\
\hline $22(\%)$ & $3(2)$ & 0 & \\
\hline $23(\%)$ & $17(9)$ & $53(27)$ & \\
\hline $25(\%)$ & $53(27)$ & $61(31)$ & \\
\hline $27(\%)$ & $62(31)$ & $56(28)$ & \\
\hline $29(\%)$ & $58(29)$ & $18(9)$ & \\
\hline $\begin{array}{l}\text { Patch enlargement of the aortic } \\
\text { annulus }(\%)\end{array}$ & 0 & $43(22)$ & 0.001 \\
\hline Body surface area $\left(\mathrm{m}^{2}\right)^{*}$ & $1.84 \pm 0.21$ & $1.85 \pm 0.22$ & 0.49 \\
\hline Aortic crossclamp time $(\mathrm{min})^{*}$ & $84 \pm 23$ & $69 \pm 27$ & 0.001 \\
\hline $\begin{array}{l}\text { Cardiopulmonary bypass } \\
\text { time }(\mathrm{min})^{*}\end{array}$ & $105 \pm 30$ & $94 \pm 35$ & 0.002 \\
\hline
\end{tabular}

${ }^{*}$ Expressed as mean \pm standard deviation.

\section{Results}

Patient survival. There were 9 deaths in the group who received the Toronto SPV bioprosthesis and 25 deaths in the group who received the Hancock II $(p=0.004)$. Fig. 1 shows the actuarial survival for both groups. The survival was significantly better in the Toronto SPV group $(p=0.006)$. There were 5 cardiac deaths in the Toronto SPV group and 15 cardiac deaths in the Hancock II group. Fig. 2 shows the freedom from cardiac death in both groups of patients. The freedom from cardiac death was significantly better in the Toronto SPV group $(p=0.01)$. There was only one valverelated death in the Toronto SPV group and four deaths in the Hancock II group. The freedom from valve-related death at 8 years was $99 \% \pm 1 \%$ for the 


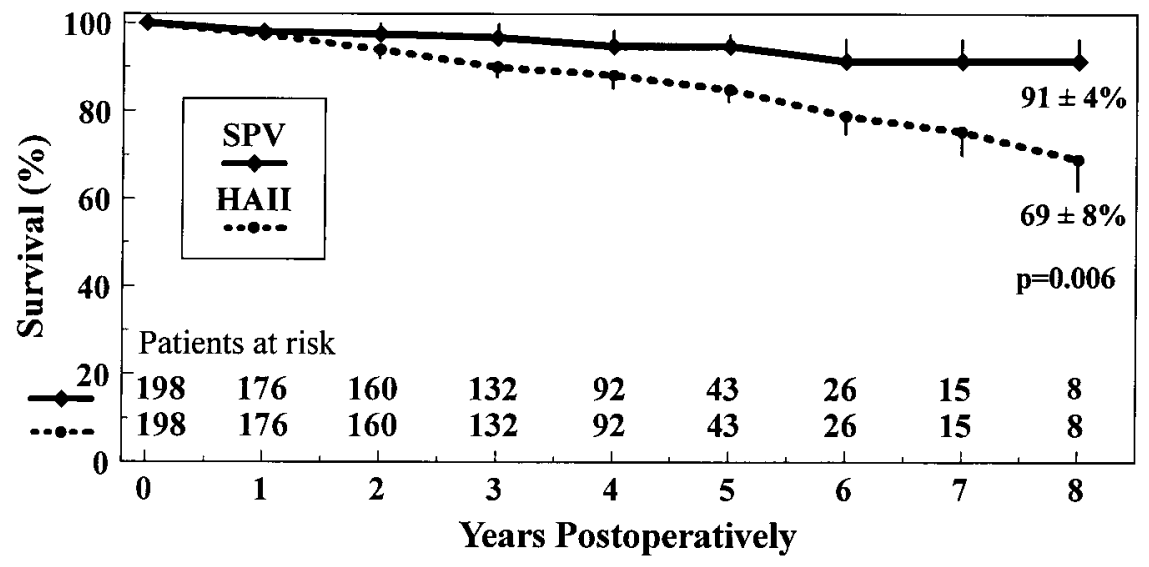

Fig. 1. Actuarial survival after AVR with Toronto SPV and Hancock II (HAII) bioprostheses.

Toronto SPV and $97 \% \pm 2 \%$ for the Hancock II ( $p=$ not significant). Table II shows the causes of late deaths.

Thromboembolism. There were 10 thromboembolic events (two strokes and eight transient ischemic attacks) in the Toronto SPV group and 14 (six strokes and eight transient ischemic attacks) in the Hancock II group. The freedom from thromboembolic complications at 8 years was $91 \% \pm 4 \%$ for the Toronto SPV and $86 \% \pm 5 \%$ for the Hancock II $(p=0.07)$.

Infective endocarditis. Infective endocarditis developed in two patients with the Toronto SPV (one early and one late), and in six patients with the Hancock II (one early and five late). The freedom from infective endocarditis at 8 years was $98 \% \pm$ $2 \%$ for the Toronto SPV and $94 \% \pm 2 \%$ for the Hancock II $(p=0.05)$.

Reoperation. Redo AVR was necessary in two patients with the Toronto SPV bioprosthesis (both for endocarditis) and in eight patients with the Hancock II (six for endocarditis and two for primary tissue failure). The freedom from redo AVR at 8 years was $98 \% \pm 2 \%$ for the Toronto SPV bioprosthesis and $83 \% \pm 9 \%$ for the Hancock II $(p=0.03)$.

Valve-related morbidity. Fig. 3 shows the freedom from any valve-related complication for both groups of patients. The difference was statistically significant in favor of the Toronto SPV bioprosthesis $(p=0.05)$.

Predictors of clinical outcomes by multivariate analysis. The following variables were submitted to a Cox proportional hazard model: age $(<65$ years and $\geq 65$ years), left ventricular dysfunction (ejection fraction, $>30 \%$ and $\leq 30 \%$ ), New York
Heart Association (classes I through III and class IV), coronary artery disease, and valve type (Toronto SPV and Hancock II). Aortic stenosis was also tested because there were more patients with aortic stenoses in the Toronto SPV bioprosthesis than in the Hancock II group (Table I) but it was not a predictor of outcome. The results of this analysis are shown in Table III. The overall mortality rate, the cardiac mortality rate, and the risk of valve-related morbidity rate after AVR with the Toronto SPV bioprosthesis were lower than with the Hancock II.

\section{Discussion}

This case-control study shows that the late clinical outcomes after AVR with an SPV are significantly better than those of a stented porcine valve. Although it is possible that these differences may have been due to bias in patients' selection or other confounding factors not detected in our cardiovascular database, we believe that our findings are a consequence of AVR with a bioprosthesis with excellent hemodynamic features.

Assessing potential bias and confounding factors. Patients were matched by an epidemiologist who had no knowledge of the valves or of the clinical outcomes. Careful review of each patient's clinical profile failed to indicate any bias as far as the severity of the cardiac disease or of the associated diseases such as diabetes, hypertension, peripheral vascular disease, renal function impairment, or any malignancy that may have affected the surgeon's choice of the valve in the matched patients. However, there was a higher number of noncardiac deaths among patients with the Hancock II valve, 


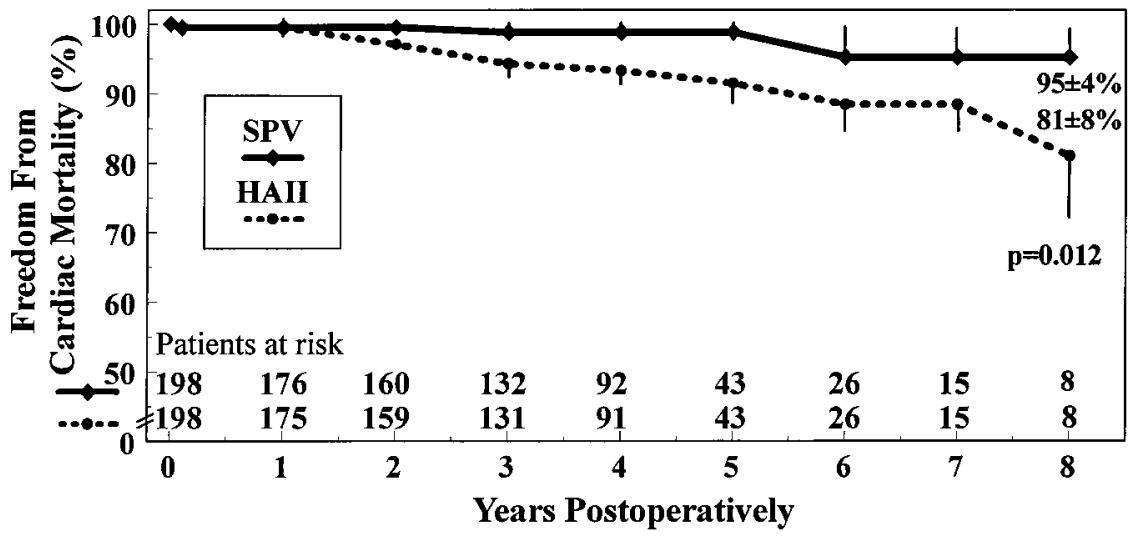

Fig. 2. Freedom from cardiac death after AVR with Toronto SPV and Hancock II bioprostheses.

and this finding could not be explained by examining the preoperative variables.

Table I shows a higher incidence of aortic stenosis among patients who received the Toronto SPV bioprosthesis when compared with patients who received the Hancock II bioprosthesis. This is probably due to the fact that the Toronto SPV bioprosthesis was not implanted in patients with a dilated aortic root. Nevertheless, aortic stenosis was not a predictor of clinical outcomes by univariate analysis ( $\chi^{2}$ and Fisher's exact test) or multivariate analysis (Cox regression analysis) in the entire population or in any of its subgroups (Hancock II sampled and not sampled or Toronto SPV).

To evaluate the potential bias of the Hancock II patients, the sampled group of (198 patients) was compared with the not sampled (468 patients). The actuarial survival at 8 years was $69 \% \pm 5 \%$ for the sampled group and $70 \% \pm 3 \%$ for the not sampled group of Hancock II patients $(p=0.34)$. The freedom from cardiac deaths and the freedom from valve-related deaths were also similar for the sampled and not sampled groups of Hancock II.

The clinical outcomes after AVR with the Toronto SPV bioprosthesis have been exceptionally good, particularly when compared with other reports on stented bioprostheses. ${ }^{6,10-13}$ In our experience with 242 patients with a mean age of 62 years and coronary artery disease in one third of those patients, the actuarial survival including the operative mortality rate was $89 \%$ at 9 years. ${ }^{6}$ Similarly, in the premarked clinical trial involving over 600 patients (mean age, 67 years; coronary artery disease, $40 \%$ ) sponsored by the manufacturer of this valve to obtain its Food and Drug Administration approval, the actuarial survival at 6 years was approximately
Table II. Causes of late deaths

\begin{tabular}{lcc}
\hline & Toronto SPV & Hancock II \\
\hline Cardiac and valve-related deaths & & \\
$\quad$ Myocardial infarction/sudden & 3 & 5 \\
Congestive heart failure & 1 & 6 \\
Prosthetic valve endocarditis & 1 & 2 \\
$\quad$ Stroke & 0 & 2 \\
Noncardiac deaths & 2 & 5 \\
Cancer & 0 & 2 \\
Renal failure & 0 & 2 \\
Abdominal aortic aneurysm & 0 & 1 \\
Pneumonia & 1 & 0 \\
Cerebral aneurysm & 1 & 0 \\
Suicide &
\end{tabular}

$90 \% .^{10}$ The rates of valve-related complications have also been lower than those observed with other stented bioprostheses. ${ }^{6,10-13}$ In most reports on late outcomes after AVR with stented biologic valves, the actuarial survival at 5 years ranged around $70 \%$ to $80 \%$ and at 10 years ranged around $50 \%$ to $60 \% .^{11-13}$

Hemodynamic performance of the Toronto SPV bioprosthesis. Numerous studies have shown that the Toronto SPV bioprosthesis has excellent hemodynamic features that are comparable with those of the aortic valve homograft. ${ }^{3-5,14}$ Serial echocardiographic studies in large numbers of patients who underwent an AVR with the Toronto SPV bioprosthesis demonstrated a progressive reduction in the mean transvalvular gradients and an increase in the effective valve orifices during the first year after implantation. $^{3-4,6}$ At the end of postoperative year 1 , the mean transvalvular gradients have been consistently below $5 \mathrm{~mm} \mathrm{Hg}$ in all patients, regardless of the size of valve implanted. ${ }^{3-6}$ This favorable hemodynamic feature probably inhibits the stimulus re- 


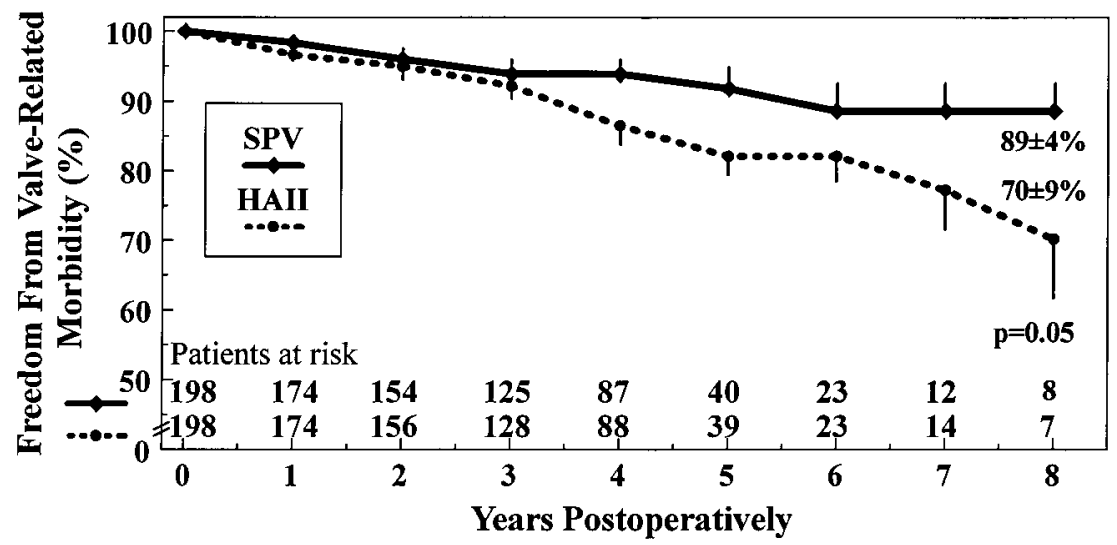

Fig. 3. Freedom from any valve-related complication after AVR with Toronto SPV and Hancock II bioprostheses.

Table III. Predictors of outcome by Cox proportional hazard model

\begin{tabular}{lrcc}
\hline Outcome & $\begin{array}{r}\text { Regression } \\
\text { coefficient }\end{array}$ & $\begin{array}{c}\text { Hazard } \\
\text { ratio }\end{array}$ & $p$ Value \\
\hline Overall deaths & & & \\
Toronto SPV & $-0.92 \pm 0.40$ & 0.40 & 0.0001 \\
LV dysfunction & $0.99 \pm 0.38$ & 2.20 & \\
CAD & $0.79 \pm 0.38$ & 2.20 & \\
Age $>65$ years & $0.78 \pm 0.40$ & 2.18 & \\
$\quad$ Male gender & $0.88 \pm 0.56$ & 2.41 & \\
Cardiac-related deaths & & & \\
$\quad$ Toronto SPV & $-1.49 \pm 0.65$ & 0.37 & 0.004 \\
$\quad$ LV dysfunction & $1.09 \pm 0.53$ & 2.98 & \\
Valve-related deaths & None & None & NS \\
Valve-related morbidity: & & & \\
$\quad$ Toronto SPV & $-0.66 \pm 0.35$ & 0.52 & 0.054 \\
\hline
\end{tabular}

$L V$, Left ventricle; $C A D$, coronary artery disease.

sponsible for left ventricular hypertrophy, and remodeling of the ventricle begins soon after operation. ${ }^{3,5}$ Although regression of left ventricular hypertrophy also occurs after AVR with stented valves, ${ }^{15-17}$ most patients still have residual hypertrophy after 2 to 3 years. ${ }^{16}$ Residual hypertrophy is rare after AVR with the Toronto SPV bioprosthesis after postoperative year 2. ${ }^{3}$ In addition, it has been shown that early postoperative left ventricular function after AVR is better with the Toronto SPV bioprosthesis than with stented porcine and mechanical valves. ${ }^{5,15}$ This observation may explain the relatively low operative mortality rate for AVR with the Toronto SPV bioprosthesis in spite of longer aortic crossclamp times than with stented valves. ${ }^{4-6}$ In our experience with porcine valves, the operative mortality rate for AVR with the
Toronto SPV bioprosthesis was $0.8 \%$, whereas for the Hancock II it was $4 \%{ }^{4,}, 11$

The long-term effects of residual left ventricular hypertrophy after AVR are unknown, but the clinical experience with systemic hypertension indicates that left ventricular hypertrophy adversely affects long-term survival. ${ }^{7,8}$ Thus it is conceivable that AVR with the Toronto SPV bioprosthesis enhances survival because of its hemodynamic features. This may well explain the differences in cardiac and valve-related deaths in our case-control study. Indeed, the major difference in clinical outcomes between our two groups of patients was in the number of late cardiac deaths. During a mean follow-up of 43 months, one third as many late deaths occurred in patients with the Toronto SPV valve as in patients with the Hancock II bioprosthesis. The frequency of valve-related complications were also significantly lower in patients who received stentless valves. This reduction in complications may also have indirectly affected survival.

Aortic valve homografts have excellent hemodynamic features and, when implanted in the subcoronary position, provide similar flows to the normal aortic valve. ${ }^{14}$ Thus one would expect that AVR with an aortic valve homograft would enhance late survival, which is what we found with the SPV bioprosthesis. Although this may not have been observed in the past, recently published results on AVR with homograft indicate a survival of $85 \%$ to $95 \%$ at 8 to 10 years, including operative mortality rates. ${ }^{18-20}$ Although the patient population in those series were different from ours, the results suggest that aortic valve ho- 
mografts provide better clinical outcomes than those obtained with stented biologic valves. Probably the same could be said about AVR with pulmonary autograft because it is also a stentless biologic valve with superlative hemodynamic qualities. Finally, we have treated numerous patients with patient-prosthesis mismatch after AVR when mechanical and stented bioprostheses were implanted, but we have never documented a case of patient-prosthesis mismatch in more than 500 AVRs with stentless biologic valves of all types.

Durability of the Toronto SPV bioprosthesis. The Toronto SPV bioprosthesis has been used only since July 1991. There has been no documented case of primary tissue degeneration, but it has been used almost exclusively in older patients. ${ }^{6,10}$ However, we implanted 29 custom-made stentless porcine aortic valves similar to the Toronto SPV bioprosthesis just over one decade ago, ${ }^{1}$ and the experience with those valves suggests that their durability is no different from that of stented porcine valves. ${ }^{6}$ If this is the case with the Toronto SPV bioprosthesis, and if this valve indeed enhances the life span after AVR, the probability of reoperation for valve failure will be greater with this valve than with stented ones because more patients will be at risk of outliving their bioprosthesis.

Limitations of the study. This was a retrospective study, and the two groups of patients may have been quite different in spite of our efforts to eliminate any potential bias and to exclude any confounding factor that may have influenced the clinical outcome. Other limitations are the relatively small number of patients in each group and the duration of follow-up.

\section{Conclusions}

This case-match study indicates that AVR with a stentless porcine aortic valve provides better clinical outcomes than with a stented porcine valve. The patients' survival, the freedom from cardiac deaths, and the freedom from valve-related complications were significantly better in patients with the stentless valve. Unfortunately all observations made were based on retrospective data with all their limitations and potential bias. However, this information is a compelling reason to believe that valves with superior hemodynamic performance have a beneficial effect in the late results of AVR.

\section{REFERENCES}

1. David TE, Ropchan GC, Butany JW. Aortic valve replacement with stentless porcine bioprostheses. J Card Surg 1988;3:501-5.
2. David TE, Pollick C, Bos J. Aortic valve replacement with stentless porcine aortic bioprosthesis. J Thorac Cardiovasc Surg 1990;99:113-8.

3. Del Rizzo DF, Goldman BS, Christakis GT, David TE. Hemodynamic benefits of the Toronto stentless valve. J Thorac Cardiovasc Surg 1996;112:1431-46.

4. Walther T, Falk V, Autschbach, et al. Hemodynamic assessment of the stentless Toronto SPV bioprosthesis by echocardiography. J Heart Valve Dis 1994;3:657-65.

5. Jin XY, Zhang ZM, Gibson DG, Yacoub MH, Pepper JR. Effects of valve substitutes on changes in left ventricular function and hypertrophy after aortic valve replacement. Ann Thorac Surg 1996;62:683-90.

6. David TE, Feindel CM, Scully HE, Bos J, Rakowski H. Aortic valve replacement with stentless porcine aortic valves: a 10-year experience. J Heart Valve Dis (in press).

7. Bikkina M, Larson MG, Levy D. Asymptomatic ventricular dysrhythmias and mortality in subjects with left ventricular hypertrophy. J Am Coll Cardiol 1993;22:1111-6.

8. Levy D, Garrison RJ, Savage DD, Kammel WB, Castelli WP. Prognostic implications of echocardiographically determined left ventricular mass in the Framingham heart study. N Engl J Med 1990;322:1561-6.

9. Edmunds LH Jr, Clark RE, Cohn LH, Grunkemeier GL, Miller DC, Weisel RD. Guidelines for reporting morbidity and mortality after cardiac valvular operations. J Thorac Cardiovasc Surg 1996;112;708-11.

10. Toronto SPV valve-PMA Clinical Section. St. Jude Medical submission to the FDA. July 3, 1997.

11. David TE, Armstrong S, Sun Z. The Hancock II bioprosthesis at ten years. Ann Thorac Surg 1995;60:S229-34.

12. Akins CW, Carroll DL, Buckley MJ, Daggett WM, Hilgenberg AD, Austen G. Late results with Carpentier-Edwards porcine bioprosthesis. Circulation 1990;82(Suppl):IV65-74.

13. Cosgrove DM, Lytle BW, Taylor PC, et al. The CarpentierEdwards pericardial aortic valve: ten-year results. J Thorac Cardiovasc Surg 1995;110:651-62.

14. Jin XY, Gibson DG, Yacoub M, Pepper RJ. Perioperative assessment of aortic homograft, Toronto stentless valve, and stented valve in the aortic position. Ann Thorac Surg 1995; 60:S395-401.

15. Cohen G, Christakis GT, Buth KJ, et al. Early experience with stentless versus stented valves. Circulation 1997; 96(Suppl):II76-82.

16. De Paulis R. Sommariva L, De Matteis GM, et al. Extent and pattern of regression of left ventricular hypertrophy in patients with small size CarboMedics aortic valves. J Thorac Cardiovasc Surg 1977;113:901-9.

17. Pibarot P, Honos GN, Durand GL, Dumesnil JG. The effect of prosthesis-patient mismatch on aortic bioprosthetic valve hemodynamic performance and patient clinical status. Can J Cardiol 1996;12:379-87.

18. Kirklin, JK, Smith D, Novick W, et al. Long-term function of cryopreserved aortic homografts: a ten-year study. J Thorac Cardiovasc Surg 1993;106:154-66.

19. Yacoub M, Rasmi RH, Sundt TM, et al. Fourteen-year experience with homovital homografts for aortic valve replacement. J Thorac Cardiovasc Surg 1995;110:186-94.

20. Doty DB, Michielon G, Wang ND, Cain AS, Millar RC. Replacement of the aortic valve with cryopreserved aortic allograft. Ann Thorac 1993;56:228-36. 